\title{
Anti-inflammatory properties of bergenin in mice
}

Guilherme A. L. Oliveira', Andreza K. S. Araujoํ, Gabriella Pacheco ${ }^{1}$, Ana P. Oliveira ${ }^{1}$, Jelson L. Carvalho ${ }^{1}$, Letícia S. Chaves $^{1}$, Gabrielle C. Sousa ${ }^{1}$, André L. F. Lopes ${ }^{1}$, Priscila C. Silva ${ }^{1}$, Ana Carolina M. Leódido ${ }^{1}$, Kerolayne M. Nogueira ${ }^{1}$, Luan K. M. Souza ${ }^{1}$, Thiago L. Araújo ${ }^{1}$, Lucas A. D. Nicolau², Jand Venes R. Medeiros ${ }^{1 *}$

${ }^{1}$ Laboratory of Pharmacology of Inflammation and Gastrointestinal Disorders (Lafidg), Federal University of Piauí, Parnaíba, Brazil. ${ }^{2}$ Department of Physiology and Pharmacology, Federal University of Ceará, Fortaleza, Ceará, Brazil.

\begin{tabular}{|c|c|}
\hline ARTICLE INFO & ABSTRACT \\
\hline Received on: 29/01/2019 & \multirow{4}{*}{$\begin{array}{l}\text { Inflammation is a protective biological reaction against infection and has undesirable effects. Although bergenin }(\mathrm{BG}) \text {, } \\
\text { a C-glycoside derivative of 4-O-methyl gallic acid, has many pharmacological properties, no study has demonstrated } \\
\text { the activity of } \mathrm{BG} \text { in inflammatory mediators, such as histamine and prostaglandin } \mathrm{E}_{2}\left(\mathrm{PGE}_{2}\right) \text {. The present study } \\
\text { investigated the anti-inflammatory activity of } \mathrm{BG} \text { obtained from Peltophorum dubium Taub, in edema models induced } \\
\text { by carrageenan and inflammatory mediators in Swiss mice. The assessment of its toxicity was also conducted. The } \\
\text { evaluations of this study indicated that the pre-treatment with } \mathrm{BG}(25 \mathrm{mg} / \mathrm{kg}) \text { significantly reduced edema induced by } \\
\text { carrageenan, compound } 48 / 80 \text {, histamine, and } \mathrm{PGE}_{2}(p<0.05) \text {. Also, pre-treatment with BG inhibited the recruitment } \\
\text { of leukocytes and neutrophils, reducing adhesion and rolling of these cells, myeloperoxidase (MPO) activity, } \\
\text { malondialdehyde (MDA) levels, and vascular permeability. Treatment with BG }(2,000 \mathrm{mg} / \mathrm{kg}) \text { showed no toxic } \\
\text { signs in hippocratic screening, weight of animals, water and feed intake, vital organs weight and histopathological } \\
\text { evaluation, and hematological and biochemical parameters. In conclusion, these results show that the BG obtained } \\
\text { from } P \text {. dubium Taub has anti-inflammatory activity against different models of inflammation, reducing neutrophil } \\
\text { migration and damage caused by oxidative stress and lipid peroxidation. BG did not present toxic effects in the } \\
\text { evaluated parameters. }\end{array}$} \\
\hline Accepted on: 17/04/2019 & \\
\hline Available online: $01 / 07 / 2019$ & \\
\hline $\begin{array}{l}\text { Key words: } \\
\text { Inflammation, edema, } \\
\text { flavonoids, toxicity. }\end{array}$ & \\
\hline
\end{tabular}

\section{INTRODUCTION}

Inflammation is a protective biological response against infection, injury, or damage. This protective mechanism eliminates aggressive agents, regenerates and repairs tissues (Taams, 2018). When the body is unable to control inflammation adequately, a chronic inflammatory disease is triggered (Daham et al., 2014; Herenius et al., 2013; Rielland et al., 2014; Singh et al., 2013; Taams, 2018; Zygmunt et al., 2014). The chronic inflammatory disease involves the overproduction of various inflammatory mediators, such as vasoactive amines, increases blood flow and vascular permeability, liberates proinflammatory cytokines from macrophages, complement system cascade, and leukocyte migration, and generates reactive

"Corresponding Author

Jand Venes R. Medeiros, Laboratory of Pharmacology of Inflammation and Gastrointestinal Disorders (Lafidg), Federal University of Piaui, Parnaiba,Brazil.E-mail: jandvenes@ufpi.edu.br oxygen species (ROS). All of these events result in tissue and DNA damage (Ashour et al., 2018; Silva et al., 2017).

Among the classes of drugs used to treat inflammation, non-steroidal anti-inflammatory drugs (NSAIDs) are the most widely used (Ferlazzo et al., 2016; Marino et al., 2015). These drugs exhibit their actions mainly by the inhibition of cyclooxygenases (COX- 1 and COX-2), which are involved in the production of prostaglandins, prostacyclins, and thromboxanes. The use of NSAIDs is closely related to the development of diseases, such as gastrointestinal disorders, hemorrhages, and renal disorders, becoming less recommended in chronic treatment (Akram et al., 2016; Cao et al., 2016; Intini et al., 2017; Perkins et al., 2015; Silva et al., 2017; Yang et al., 2018). NSAIDs are also associated with severe adverse effects and have been used to treat inflammatory disorders to date, despite their high cost (Ferlazzo et al., 2016; Sullivan et al., 2018). Due to the complications associated with the use of NSAIDs, new anti-inflammatories with better costeffectiveness and low toxicity became a therapeutic need. 
The use of secondary metabolites from nature has been presented as a promising new therapy. When compared to NSAIDs, secondary metabolites are shown to be more effective and safer for use in pathological conditions of inflammation and chronic pain (Almeida et al., 2017; Fukumitsu et al., 2016). The use of new molecules from natural products, such as monoterpenes, polyphenolic compounds, carotenoids, and flavonoids, has been heavily explored, and their anti-inflammatory potential has been demonstrated (Almeida et al., 2017; Chen et al., 2014; Gomes et al., 2017; Jang et al., 2014; Pérez et al., 2014; Silva et al., 2017; Vasconcelos et al., 2017). Among the flavonoids are c-glycoside molecules, which have been widely studied as therapeutic agents for the treatment of various diseases, including inflammatory disorders (Chen et al., 2014; Thao et al., 2016; Wang et al., 2015).

Bergenin (BG) is a C-glycoside derivative of 4-O-methyl gallic acid (Bajracharya, 2015) extracted from roots of the plant Peltophorum dubium Taub. BG is also a major constituent of ethanol extracted from the roots of this plant (Oliveira et al., 2015). Peltophorum dubium belongs to the family of legumes (Fabaceae) and the subfamily Caesalpinioideae. BG shows physicochemical properties and the structural formula $(2 \mathrm{R}, 3 \mathrm{~S}, 4 \mathrm{~S}, 4 \mathrm{aR}, 10 \mathrm{bS})$ $-3,4,8,10$ - tetrahydroxy-2- (hydroxymethyl) -9-methoxy-3,4,4a, 10b-tetrahydro-2H-pyrano [c] isochromen-6-one $\left(\mathrm{C}_{14} \mathrm{H}_{16} \mathrm{O}_{9}\right)$, as shown in Figure 1 (Bajracharya, 2015; Oliveira et al., 2015).

The studies have shown that the BG has anti-inflammatory properties, being able to selectively inhibit COX-2 in vitro (Nunomura et al., 2009), besides having an important role in the reduction of inflammatory pain (Oliveira et al., 2011), chronic bronchitis (Ren et al., 2016), and Lipopolysaccharid (LPS)-induced mastitis, on in vivo models (Gao et al., 2015). However, no studies have demonstrated the role of BG in classical models of inflammation and its action on inflammatory mediators as histamine and $\mathrm{PGE}_{2}$.

Therefore, the present study evaluated the possible anti-inflammatory effects of BG in mice and assessed if toxicological effects are associated with the administration of this compound.

\section{MATERIALS AND METHODS}

\section{Isolation of BG from $P$. dubium (spreng.) Taub}

The peels of the P. dubium Taub roots found at the Ondina Campus of the Federal University of Bahia, Salvador-BA, Brazil, were collected. A sample was placed in the herbarium Alexandre
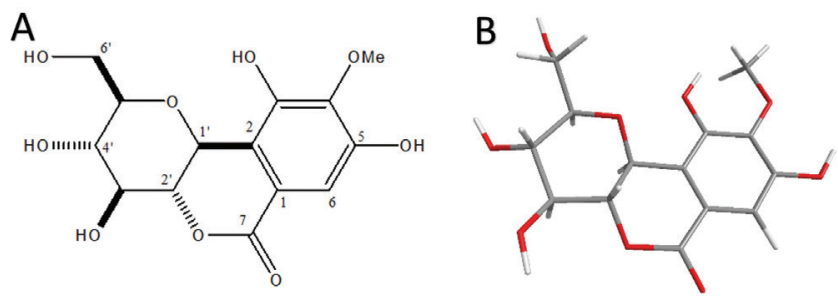

Figure 1. The molecular structure of bergenin. (A) Chemical structure of bergenin (own authorship). (B) ORTEP projection of bergenin, determined and analyzed by X-ray diffraction. Adapted from Oliveira et al. (2017).
Leal da Costa, from the Institute of Biology of UFBA, under cataloging number 69237. Isolation and purification of BG from material obtained was performed according to Oliveira et al. (2017).

\section{Drugs and reagents}

$\lambda$-Carrageenan (CG), indomethacin (INDO), compound 48/80, histamine, and $\mathrm{PGE}_{2}$ were purchased from Sigma-Aldrich (Saint Louis, MO). Heparin was provided by Merck, from Sao Paulo, Brazil. Saline solution sterile $0.9 \%$ (w/v) $\mathrm{NaCl}$ (SAL) was used to dilute all the drugs. All other chemicals used in the experiment had degree analytical and obtained from the standard commercial suppliers.

\section{Animals}

Male Swiss mice (25-30 g) from the Federal University of Piauí were used in the experiment. These animals remained in an environment with the temperature of $22^{\circ} \mathrm{C}$ in a 12 hours light/ dark cycle. The experimental groups contained five or six animals. Animal treatments and surgical approaches proceeded according to the National Institute of Health (Bethesda, MD). The experimental protocol used was approved by the ethics committee of the Federal University of Piauí with the protocol number, 220/16.

\section{Anti-inflammatory assays}

\section{Effects of BG in carrageenan-induced paw edema}

The pre-treatment of the mice was performed with BG $(5,25,50,100 \mathrm{mg} / \mathrm{kg}$, i.p.) or INDO (10 g/kg, i.p.), 30 minutes before the administration of $50 \mu \mathrm{l}$ carrageenan $(500 \mu \mathrm{g} / \mathrm{paw})$ on the right hind paw. A $0.9 \%$ sterile saline solution was administered to the negative control group. The paw volume of all mice was measured before and after the administration of inflammatory stimulus, as described by Offergeld et al. (1992).

\section{Effects of BG in paw edema induced by compound 48/80, histamine} and $P G E 2$

The pre-treatment of the animals was carried out from the injection of BG (25 mg/kg, i.p.), INDO (10 mg/kg, i.p.), or saline $(0.9 \%, w / v, \mathrm{NaCl}$-negative control). After 30 minutes, it was performed administration of $50-\mu \mathrm{L}$ histamine $(100 \mu \mathrm{g} / \mathrm{paw})$, compound 48/80 (12 $\mu \mathrm{g} / \mathrm{paw})$, or PGE2 (3 nmol/paw), in the right hind paw, for the induction of edema, or of $0.9 \%$ saline in the negative control group. The experiment was carried out following the methodology used by Chintalwar et al. (1999) and Maling et al. (1974).

\section{Carrageenan-induced peritonitis}

First, was utilized saline $(0.9 \%)$, INDO $10 \mathrm{mg} / \mathrm{kg}$, or BG $25 \mathrm{mg} / \mathrm{kg}$ for pre-treatment of mice. Thirty minutes later, carrageenan was injected into the animals $(250 \mu \mathrm{l}, 500 \mu \mathrm{g} /$ cavity $)$. The protocol was followed according to Silva et al. (2017). The results are presented as leukocyte or neutrophil number per milliliter of peritoneal exudate.

\section{Intravital microscopy of leukocytes}

Intravital microscopy was used to evaluate the rolling and adhesion of leukocytes in the mesenteric microcirculation, as previously described (Fortes et al., 1991; Silva et al., 2015). 
The induction protocol was the one that was used in the peritonitis model; however, the anesthesia with ketamine $(100 \mathrm{mg} / \mathrm{kg}$, i.p.) and xylazine (10 $\mathrm{mg} / \mathrm{kg}$, i.p.) was performed in mice in the third hour. The mesenteric tissue was then externalized so that microscopic analysis could be performed in situ.

\section{Myeloperoxidase concentration}

Myeloperoxidase (MPO) activity of the peritoneal exudate was analyzed according to the method described previously (Bradley et al., 1982). The results are expressed as units of MPO per milliliter of peritoneal exudate $(\mathrm{UMPO} / \mathrm{ml})$.

\section{Malondialdehyde concentration}

The Malondialdehyde (MDA) concentration was measured according to a method previously described by Uchiyama and Mihara (1978). The butanolic phase was read at 535 and $520 \mathrm{~nm}$. The difference between the two measurements was determined. The MDA values are expressed as nmol MDA/g tissue.

\section{Vascular permeability assay}

Animals were pretreated with saline $(0.9 \%)$, INDO $(10 \mathrm{mg} / \mathrm{kg})$, or BG $(25 \mathrm{mg} / \mathrm{kg})$. Carrageenan $(250 \mu \mathrm{l}, 500 \mu \mathrm{g} /$ cavity) was then administered 30 minutes following pre-treatment. The vascular permeability was then verified by measuring the extravasation of Evans blue. The reading of the samples was performed with spectrophotometer at $620 \mathrm{~nm}$ (Silva et al., 2013).

\section{Acute toxicity study of BG}

The toxicity of bergenin was determined according to the parameters of the Organization for Economic Co-operation and Development (Guideline 423/2001) (OECD, 2001). The dose of $2,000 \mathrm{mg} / \mathrm{kg} \mathrm{BG}$ was administered, while the control group received only saline. The animals' clinical parameters were analyzed for 14 days, followed by hematological, biochemical, and histological analysis.

\section{Statistical analysis}

Results are expressed as mean \pm standard error of the mean $( \pm$ SEM). GraphPad Prism statistical software version 6.0 (GraphPad Software Inc., San Diego, CA) was used for statistical analysis. The variables presented normal distribution and differences between the values for groups were evaluated using analysis of variance and Student-Newman-Keuls post hoc test. The Kruskal Wallis nonparametric test, followed by Dunn's test was used for histopathological evaluation. Differences between groups were considered statistically significant when $p<0.05$.

\section{RESULTS AND DISCUSSION}

\section{Anti-inflammatory assays}

\section{Effects of BG on carrageenan-induced paw edema}

In this research, the action and anti-inflammatory mechanisms of BG was elucidated, since this flavanoid demonstrates great potential in the reduction of cytokines and other agents involved in the inflammatory disorders (Gao et al., 2015; Oliveira et al., 2011). For this was evaluated the action of BG on carrageenan-induced paw edema, a model widely used in studies to assess the anti-inflammatory activity of new compounds with pharmacological potential (Fezai et al., 2013; Trevisan et al., 2014)

Carrageenan promotes the formation of edema, and its effects are related to the release of inflammatory mediators that increase vascular permeability and leukocyte migration (Huang et al., 2011). This agent triggers in its first phase (1-2 hours after CG administration) an increase in vascular permeability resulting from the release of histamine and serotonin from the mast cells (Maling et al., 1974; Silva et al., 2017). The second phase of GC response (3-4 hours) is characterized by an inflammatory infiltrate, bradykinin release, $\mathrm{PGE}_{2}$, cytokines (e.g., interleukin 1 beta (IL-1 $\beta)$, tumor necrosis factor -Alpha (TNF- $\alpha$ ), and interleukin 10 (IL-10)), and nitric oxide (Medzhitov, 2008; Silva et al., 2017). In this study, paw edema significantly increased 1 hour after carrageenan administration $(0.046 \pm 0.008 \mathrm{ml})$, with peak edema observed at the third hour $(0.100 \pm 0.007 \mathrm{ml})$, followed by a decline by the fourth hour, as shown in Figure $2 \mathrm{~A}$ and $\mathrm{C}$. The dose of $25 \mathrm{mg} / \mathrm{kg}$ BG had significant $(p<0.05)$ effects on reducing carrageenan-induced paw edema at the third hour $(0.024$ $\pm 0.008 \mathrm{ml}$, with $76 \%$ inhibition); this was also observed with INDO $(0.032 \pm 0.009 \mathrm{ml}$, inhibition of $68 \%)$.

Because the dose of $25 \mathrm{mg} / \mathrm{kg}$ of BG presented the best effect among all concentrations used in the study, it was selected for use in the next trials. The present research showed that the BG administration promoted the reduction of paw edema and corroborated with the results presented by Gao et al. (2015), in which BG acted as an anti-inflammatory agent in mastitis induced by LPS. Our results are similar to those presented by Oliveira et al. (2011) in which BG isolated from Cenostigma gardnerianum Tul. (Leguminosae) demonstrated anti-inflammatory activity in Complete Freund's adjuvant-induced paw inflammation. However, in the model of edema used to perform the antiinflammatory screening of BG in the present study the best dose was $25 \mathrm{mg} / \mathrm{kg}$, while Oliveira et al. (2011) used higher doses in the measurement of the anti-inflammatory capacity of BG, given

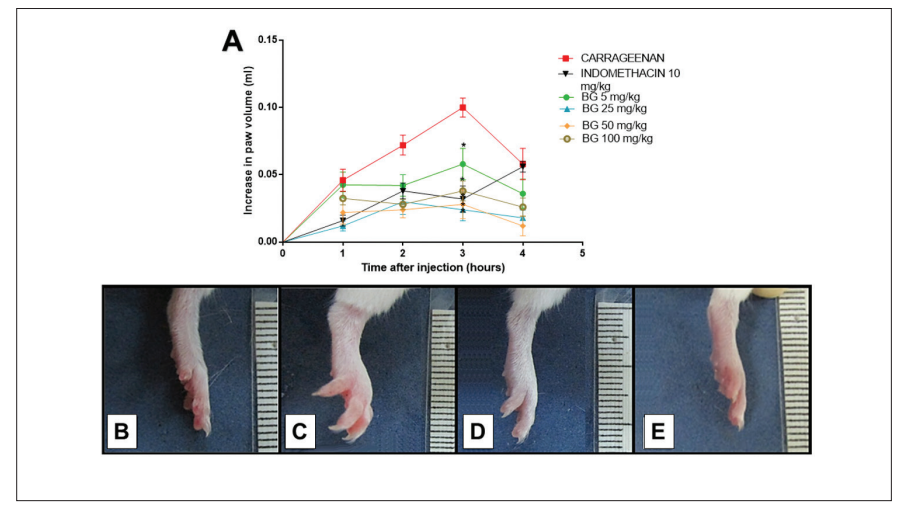

Figure 2. Bergenin decreases carrageenan-induced paw edema. Mice were pretreated with saline $(0.9 \%)$, bergenin $(5,25,50$, and $100 \mathrm{mg} / \mathrm{kg}$, i.p. $)$, or INDO (10 mg/kg, i.p.). After 30 minutes, $500 \mu \mathrm{g} /$ paw of carrageenan was administered. (A) Each line represents the mean \pm SEM (five to six mice). Photographs of the paw of mice showing normal volume (B), increased volume with carrageenan (C), decreased volume with pretreatment with BG (D), and INDO (E). Results were analyzed using one-way analysis of variance followed by Newman-Keuls test. ${ }^{*} p<0.05$ compared to the carrageenan group. 
the fact that doses of 50 and $100 \mathrm{mg} / \mathrm{kg}$ were more effective in the inflammatory pain model.

Effects of BG on paw edema induced by compound 48/80, histamine, and PGE2

As shown, BG had a better impact on the second phase of edema formation induced by carrageenan. This finding suggests that its anti-inflammatory action is related to the modulation of inflammatory mediators, cytokines, and decreased neutrophil infiltrate. Because of this result, we evaluated the mechanisms of BG in anti-edematogenic activity through the administration of inflammatory mediators, compound 48/80, histamine, and $\mathrm{PGE}_{2}$.

Compound 48/80 has already been well-established as a potent inducer of mast cell degranulation. This polymer can cause rapid release of inflammatory substances as histamine and other mediators such as serotonin, leukotrienes, and a variety of cytokines related to the inflammatory process and the formation of osmotic edema (Jang et al., 2014; Maling et al., 1974; Nishikawa and Kitani, 2008; Silva et al., 2014). Histamine is considered as a potent vasoactive mediator, and its release has been associated with vasodilation and increased vascular permeability, allowing the extravasation of plasma proteins and intravascular fluid to the interstitium. These processes then lead to the consequent formation of edema (Chimona et al., 2008; Kalokasidis et al., 2009; Kim et al., 2005; Nunes-Neto et al., 2017).

Still according to the literature data cited above, our results (Fig. 3) demonstrate the compound 48/80-induced edema $(0.086 \pm 0.013 \mathrm{ml}$, Fig. $3 \mathrm{~A})$ and histamine-induced edema $(0.056$ $\pm 0.005 \mathrm{ml}$, Fig. 3B). The edemas peak appear 30 minutes after of 48/80 and histamine administration, declining its action after 60 minutes of its administration, corroborating with others studies (Silva et al., 2015; 2017). Pre-treatment with BG (25 mg/kg) significantly inhibited $(p<0.05)$ edema induced by the compound $48 / 80$ (83.72\% inhibition), and histamine-induced paw edema (28.57\% inhibition) at the time when the agent caused a greater volume of edema in the paw. Indomethacin, the standard drug used, also significantly $(p<0.05)$ inhibited the paw edema induced by the inflammatory mediators used. In addition to confirming the anti-edematogenic effects, these results suggest that the BG influences in the release and/or action of inflammatory mediators. BG was able to inhibit the paw edema caused by the compound $48 / 80$, which may be acting in the preservation of the mast cells membrane, preventing the degranulation of these cells and consequent release of vasoactive amines, such as histamine (Maling et al., 1974; Nishikawa and Kitani, 2008; Silva et al., 2014). Besides, BG also inhibited histamine-induced edema, showing the modulation of BG in this agent related to the formation of edema, which is related to the increase of vasodilation and vascular permeability, an important inflammatory response (Kalokasidis et al., 2009; Nunes-Neto et al., 2017). The literature reports that other flavonoids are involved both in inhibiting the release of histamine by mast cells and in their antihistaminic activity, inhibiting the effects caused by the direct administration of this vasoactive amine, which corroborates with our findings (Bhatia and Paliwal, 2014; Singh et al., 2015; Wilson et al., 1951).

$\mathrm{PGE}_{2}$ is a relevant mediator to trigger vascular changes, being important for increased prostaglandin production and maintenance of the inflammatory process (Buadonpri et al., 2009).
In this study, PGE2-induced edema presented a peak 30 minutes after its administration $(0.070 \pm 0.006 \mathrm{ml}$, Fig. $3 \mathrm{C})$, corroborating with the literature (Silva et al., 2013; 2015), and BG reduced this edema ( $60 \%$ inhibition). This effect may indicate that BG possibly acts on the activity or site of action of $\mathrm{PGE}_{2}$ since other flavonoids act by suppressing the expression of the $\mathrm{PGE}_{2}$ receptor, EP1, in its biological effects (Jin et al., 2012; Kiraly et al., 2016). Besides, this potent vasodilator is related to the production of chemoattractants, such as proinflammatory cytokines (TNF- $\alpha$ and IL-1 $\beta$ ), related to the migration of leukocytes to the site of inflammation (Herrmann et al., 1990). Indomethacin also significantly $(p<0.05)$ inhibited this edema, corroborating with the literature data (Silva et al., 2017; Sousa-Neto et al., 2018).

BG extracted from Mallotus philippenensis has potent activity in the inhibition of inflammatory mediators, as it has been documented in the study by Shah et al. (2012), in which BG inhibited the action of nitric oxide and TNF- $\alpha$ in macrophages. The study by Gao et al. (2015) also demonstrated its potent activity where, in addition to the mediators above, $\mathrm{BG}$ also inhibited the expression of IL-1 $\beta$ and IL-6.

Rolling, adhesion, and migration of inflammatory cells to the injured site

The displacement of the leukocytes, in particular, the neutrophils, is an important phenomenon for the line of defence of the host, where the infiltration in injured tissues is a hallmark signs of acute inflammatory response. Thus, we evaluated the migration of leukocytes and neutrophils to the peritoneal cavity and the possible mechanism of interaction in cell recruitment in carrageenan-induced leukocyte rolling and adhesion in mesenteric postcapillary venules (Barth et al., 2016; Cano et al., 2016; Fayngerts et al., 2017; Muller, 2014; Pietrosimone and Liu, 2015). This procedure was based on the potential reduction of paw edema induced by inflammatory mediators by BG, mainly by the modulation of $\mathrm{PGE}_{2}$, involved in the production of chemoattractants.

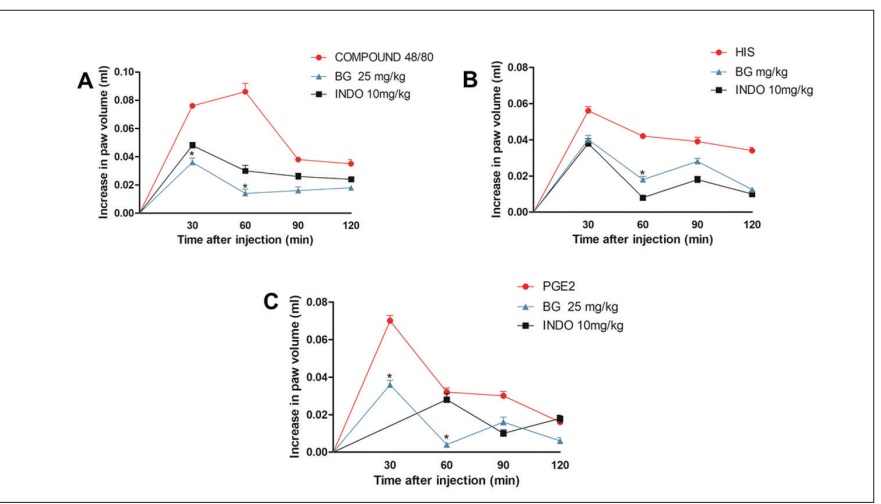

Figure 3. Bergenin decreases paw edema induced by various mediators. Mice were pretreated with saline $(0.9 \%)$, bergenin $(25 \mathrm{mg} / \mathrm{kg}$, i.p.), or INDO $(10 \mathrm{mg} /$ $\mathrm{kg}$, i.p.). After 30 minutes, paw edema was induced by compound 48/80 (12 $\mu \mathrm{g} /$ paw-A), histamine (100 $\mu \mathrm{g} / \mathrm{paw}-\mathrm{B})$, or $\mathrm{PGE}_{2}(3 \mathrm{nmol} / \mathrm{paw}-\mathrm{C})$. Each line represents the mean \pm SEM (five to six mice). Results were analyzed using oneway analysis of variance followed by Newman-Keuls test. $\# p<0.01$ compared to the saline group, ${ }^{*} p<0.05$ compared to the control group. 
Corroborating with the literature, carrageenan administration increased the total leukocyte and neutrophil count in the peritoneal lavage $\left(19.300 \pm 1.08410^{3}\right.$ cells $/ \mathrm{ml}$; $8.185 \pm 0.83310^{3}$ cells $/ \mathrm{ml}$, respectively), when compared to the control group $\left(8.170 \pm 1.08410^{3} \mathrm{cells} / \mathrm{ml} ; 0.9366 \pm 0.197510^{3}\right.$ cells/ml, respectively), as shown in Figure 4. The pre-treatment with BG significantly decreased the leukocyte $\left(8.890 \pm 2.09910^{3}\right.$ cells/ml, Fig. 4A) and neutrophil count $\left(4.828 \pm 0.59510^{3}\right.$ cells/ $\mathrm{ml}$, Fig. 4B) 4 hours after the carrageenan treatment. Pre-treatment with INDO also caused a reduction $(p<0.05)$. These results corroborate with other types of flavonoids that reduce cell migration in the carrageenan-induced peritonitis model (Furtado et al., 2016; Mitra et al., 2015; Rosa et al., 2016). Also, BG extracted from Mallotus japonicus was also observed to inhibit the production of proinflammatory cytokines (Takahashi et al., 2003) that are directly related to neutrophil recruitment.

Carrageenan administration also promoted a significant increase $(p<0.001$; Fig. 5$)$ in leukocyte rolling and adhesion to the endothelium of mesenteric vessels in intravital microscopy $(10.250 \pm 1.031$ leukocyte rolling/minute and $1.650 \pm 0.184$ adherent cells $/ 100 \mathrm{~mm}^{2}$, respectively) when compared to the negative control group $(1.600 \pm 0.509$ leukocyte rolling/minute and $0.000 \pm 0.089$ adherent cells $/ 100 \mathrm{~mm}^{2}$, respectively). However, the administration of $\mathrm{BG}(25 \mathrm{mg} / \mathrm{kg})$ significantly reduced $(p<0.001)$ the leukocyte rolling (Fig. 5A) $(4.00 \pm 0.707$ leukocyte rolling/minute) and adherence (Fig. 5B) (0.700 \pm 0.089 adherent cells $\left./ 100 \mu \mathrm{m}^{2}\right)$. BG, when significantly inhibits leukocyte rolling and adhesion, corroborates with edema measurements and leukocyte counts, in agreement with research that showed that BG inhibits cell migration in chronic bronchitis (Ren et al., 2016). These results indicate that BG may also be involved in the modulation of mechanisms related to the regulation of endothelial adhesion, which deserves further investigated. Other flavonoids are also involved with the transendothelial leukocyte migration (Herr et al., 2014; Werner et al., 2015).

Thus, from the analysis of these results, the study suggests that BG decreases the recruitment, bearing, and adhesions of leukocytes in the vascular endothelium. This decrease is probably due to the modulation of inflammatory mediators, histamine, and

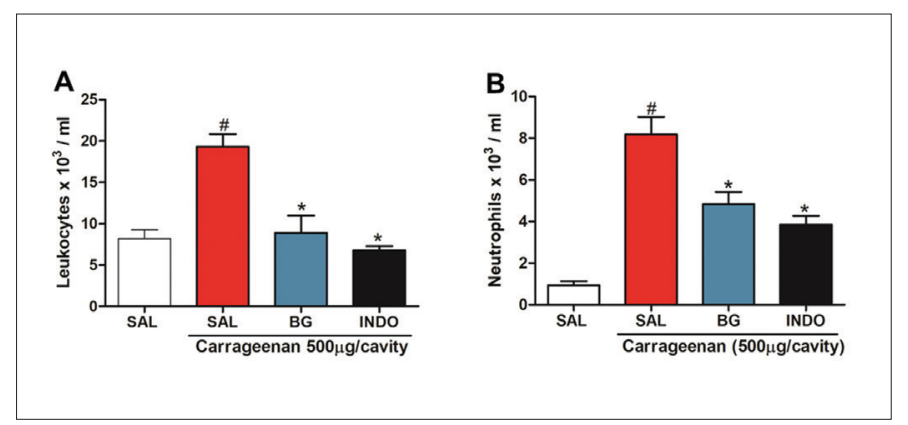

Figure 4. Bergenin reduces cell migration in carrageenan-induced peritonitis. Mice were pretreated with saline $(0.9 \%)$, bergenin $(25 \mathrm{mg} / \mathrm{kg}$, i.p.) or INDO (10 $\mathrm{mg} / \mathrm{kg}$, i.p.). After 30 minutes, $500 \mu \mathrm{g} /$ cavity of carrageenan was administered. Neutrophil migration was evaluated after 4 hours. (A) Total counts and (B) differential counts. Each bar is the mean \pm SEM (five to six mice). Results were analyzed with one-way analysis of variance and Newman-Keuls test. $\# p<0.01$ compared to the saline and $* p<0.05$ compared to the control group.
$\mathrm{PGE}_{2}$, related to the production of chemoattractant cytokines, increased blood vessel dilation, and vascular permeability, reducing the number of leukocytes, mainly neutrophils, chemoattractant by pro-inflammatory cytokines, which decreases the neutrophil bearing and adhesion to the blood vessels, and their migration to the inflammatory site.

\section{Effect of BG on myeloperoxidase activity}

Carrageenan administration produced a significant increase in myeloperoxidase activity $(12.550 \pm 2.840 \mathrm{U} / \mathrm{mg}$ of peritoneal exudate, $p<0.05)$, an important marker of neutrophil infiltration. Pre-treatment with BG $(25 \mathrm{mg} / \mathrm{kg})$ significantly reduced MPO levels $(3.951 \pm 1.529 \mathrm{U} / \mathrm{mg}$ of peritoneal exudate, $p<0.05)$, and was similar to the $0.9 \%$ saline control group (3.280 $\pm 1.992 \mathrm{U} / \mathrm{mg}$ of peritoneal exudate) as shown in Figure 6A. MPO is a peroxidase enzyme that is most abundantly expressed in neutrophilic granulocytes (Uchiyama and Mihara, 1978). In this study, it was observed that BG reduced the levels of MPO that were increased with the administration of carrageenan, confirming inhibition of neutrophil migration to the inflamed tissue. Other studies performed with BG isolated from the herb Saxifraga

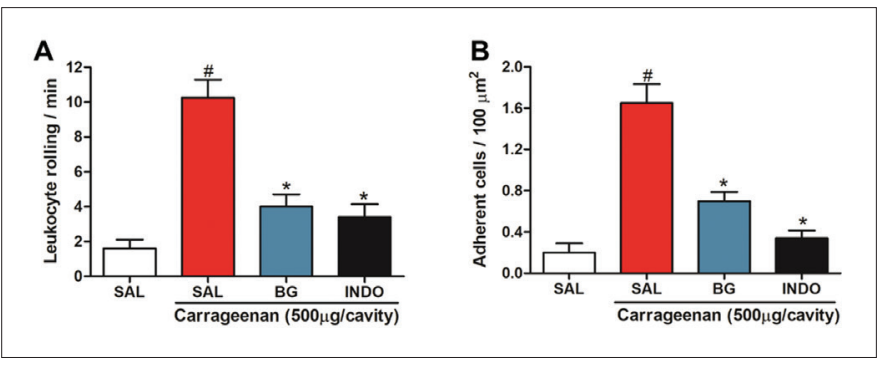

Figure 5. Bergenin reduces leukocyte-endothelial interactions. Mice were pretreated with saline $(0.9 \%)$, bergenin $(25 \mathrm{mg} / \mathrm{kg}$, i.p.), or INDO $(10 \mathrm{mg} / \mathrm{kg}$, i.p.). After 30 minutes, $500 \mu \mathrm{g} /$ cavity of carrageenan was administered. (A) The leukocyte rolling is expressed as the number of passing leukocytes per minute. (B) The number of adherent leukocytes is expressed as the number of adherent cells $/ 100 \mu \mathrm{m}^{2}$. Each bar represents the mean \pm SEM (five to six mice). Results were analyzed using one-way analysis of variance followed by Newman-Keuls test. $\# p<0.001$ compared to the saline group, ${ }^{*} p<0.001$ compared to the control group.

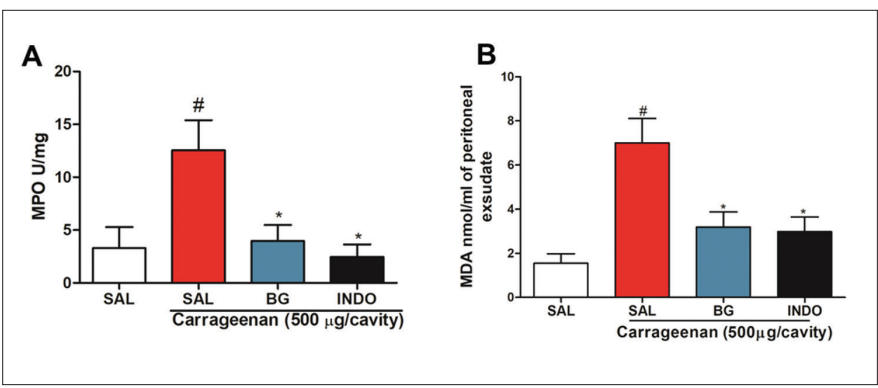

Figure 6. Bergenin decreases MPO activity and MDA levels. Mice were pretreated with saline $(0.9 \%)$, bergenin $(25 \mathrm{mg} / \mathrm{kg}$, i.p. $)$, or INDO $(10 \mathrm{mg} / \mathrm{kg}$, i.p.). After 30 minutes, $500 \mu \mathrm{g} /$ paw of carrageenan was administered. Each bar represents the mean \pm SEM of values of MPO activity (A) and MDA levels (B) (five to six mice). Results were analyzed using one-way analysis of variance followed by Newman-Keuls test. (A) $\# p<0.05$ compared to the saline group, $* p<0.05$ compared to the control group. (B) $\# p<0.01$ compared to the saline group, ${ }^{*} p<0.01$ compared to the control group. 
stolonifera Curt (Hu-Er-Cao) have already demonstrated the potential of BG in reducing MPO levels (Wang et al., 2018; Yang et al., 2017). Therefore, our results demonstrate the protective effect of BG against the infiltration of inflammatory cells.

\section{Effects of BG on malondialdehyde levels}

Neutrophilic infiltration into inflamed tissues, a result of the administration of carrageenan, is one of the characteristics of the acute innate inflammatory response, which increases ROS production (Odobasic et al., 2016; Pietrosimone and Liu, 2015). These radicals cause peroxidation of the lipid components of the cell membrane, generating the formation of lipid peroxides, which are metabolized via the oxidation to malondialdehyde. This oxidation reacts with groups of cellular proteins, resulting in metabolic disorders of the cells, tissue damage, and exacerbated inflammation (Kwiecien et al., 2014; Odobasic et al., 2016; Pietrosimone and Liu, 2015). In this way, malondialdehyde is one of the main biomarkers of the oxidative stress.

Likewise, our results showed a significant increase $(p<0.01)$ in MDA levels in the carrageenan group $(7.000 \pm 1.106 \mathrm{nmol} / \mathrm{ml}$ of peritoneal exudate) when compared to the saline group $(1.548 \pm 0.429 \mathrm{nmol} / \mathrm{ml}$ of peritoneal exudate). This present study showed that pre-treatment with BG reduced the migration of neutrophils, we evaluated if this would cause a reduction of lipid peroxidation, since oxidative stress is mainly a result of neutrophilic infiltration. The MDA levels were significantly reduced $(p<0.01)$ after pre-treatment with BG $(3.190 \pm 0.685 \mathrm{nmol} / \mathrm{ml}$ of peritoneal exudate), as can be seen in those pretreated with INDO $(2.976 \pm 0.671 \mathrm{nmol} / \mathrm{ml}$ of peritoneal exudate), in Figure 6B. Thus, the study suggests that BG decrease lipid peroxidation, possibly by reducing the oxidative stress caused by neutrophil migration.

\section{Effects of $B G$ on the vascular permeability test}

Vascular permeability, another parameter evaluated, is induced by inflammatory mediators, such as histamine and $\mathrm{PGE}_{2}$. Vessel permeability facilitates the delivery of antibodies and soluble acute phase proteins to the inflammatory site (Wilhelm, 1973). Here, we evaluated this inflammatory process using Evans blue dye, which binds to plasma proteins, mainly to albumin. In the carrageenan group, there was an increase in vascular permeability $(70.030 \pm 7.283 \mu \mathrm{g} / \mathrm{ml}$ exudate), when compared to the saline control group $(10.420 \pm 3.592 \mu \mathrm{g} / \mathrm{ml}$ exudate), as demonstrated in Figure 7. The animals pretreated with BG presented a decrease in vascular permeability that was induced by carrageenan $(37.390$ $\pm 2.466 \mu \mathrm{g} / \mathrm{ml}$ exudate); a similar result was obtained using the standard drug, INDO $(36.860 \pm 4.269 \mu \mathrm{g} / \mathrm{ml}$ exudate). These results corroborate with the decrease in histamine edema as it is directly related to increased vasodilation (Brito et al., 1997; Gros et al., 2015; Sancilio, 1969). Accordingly, we can infer that BG acts by decreasing vascular permeability by inhibiting the release of inflammatory mediators.
Also, one of the factors that facilitate transendothelial migration is the increase in vascular permeability (Aghajanian et al., 2008). BG decreased this parameter and may be one of the reasons why in our trials this flavanoid decreased the bearing and adhesion of the leukocytes in the mesenteric vessels observed in intravital microscopy.

\section{Toxicological evaluation}

$\mathrm{BG}$ at the concentration of $2,000 \mathrm{mg} / \mathrm{kg}$ showed no toxic signs in the treated mice. All animals showed normalities in the parameters: general activity, motility, heart rate, piloerection, exophthalmia, licking paws, snout, tail bite, convulsion, tail erection, tail tremor, sedation, analgesia, anesthesia and loss of reflex (data not shown), and survived throughout the experiment. No significant difference was observed concerning body weight after 14 days of the administration (Table 1). Hematological and biochemical analyses were performed for plasma levels of aspartate transaminase (AST), alanine transaminase (ALT), total direct and indirect bilirubin, liver function mediators, urea and creatinine, indicators of renal function, glucose, potassium, sodium, chlorine, and calcium. No statistical difference was observed between these parameters (Table 2).

Regarding hematology (erythrogram, leukogram, and plaque), no change was observed (Table 3). In the evaluation of the organs, spleen, kidneys, heart, and liver, no abnormalities were found in the tests or difference in their mean weights in the treated groups (Table 1). Similarly, histological analysis of spleen,

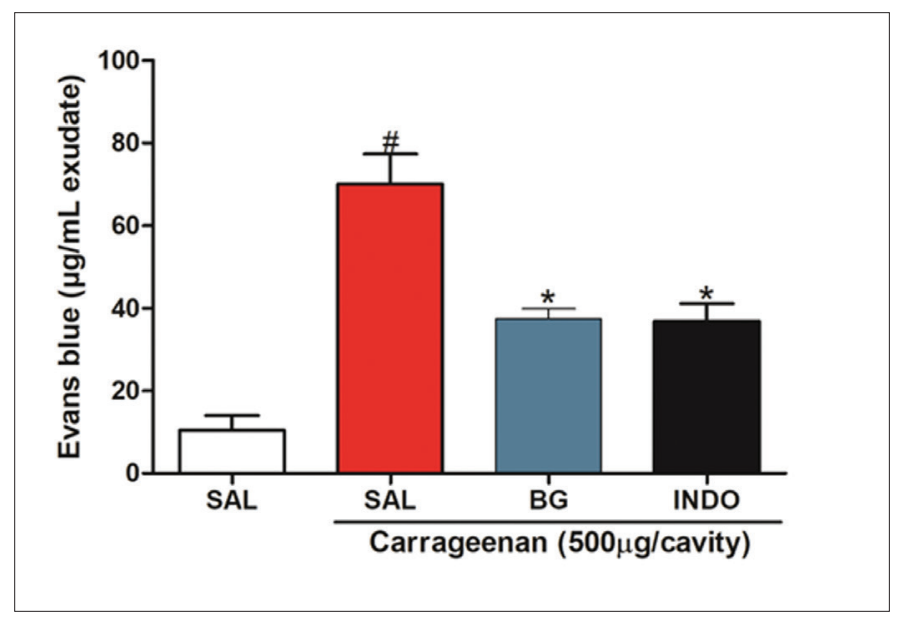

Figure 7. Bergenin acts by decreasing vascular permeability as determined by Evans blue test. Mice were pretreated with saline $(0.9 \%)$, bergenin $(25 \mathrm{mg} / \mathrm{kg}$, i.p.), or INDO (10 mg/kg, i.p.). After 30 minutes, $500 \mu \mathrm{g} /$ cavity of carrageenan was administered. Thirty minutes before euthanasia, a treatment with Evans blue $(50 \mathrm{mg} / \mathrm{kg}$ in PBS $10 \times)$ via ocular was performed. Results were analyzed using one-way analysis of variance followed by Newman-Keuls test. $\# p<0.001$ compared to the saline group, ${ }^{*} p<0.001$ compared to the control group.

Table 1. Effect of bergenin on body weight ( $\mathrm{g}$ ) and organ weight after 14 consecutive days.

\begin{tabular}{|c|c|c|c|c|c|c|}
\hline & Body weight before (g) & Body weight after (g) & Spleen (g) & Kidneys (g) & Heart (g) & Liver (g) \\
\hline Saline & $24 \pm 1.15$ & $26 \pm 1.15$ & $0.28 \pm 0.15$ & $0.30 \pm 0.02$ & $0.14 \pm 0.01$ & $1.38 \pm 0.16$ \\
\hline BG 2,000 mg $/ \mathrm{kg}$ & $21.30 \pm 1.76$ & $22.66 \pm 1.33$ & $0.12 \pm 0.01$ & $0.28 \pm 0.02$ & $0.13 \pm 0.01$ & $1.07 \pm 0.10$ \\
\hline
\end{tabular}

Values are expressed as mean $\pm \mathrm{SEM}$. Results were analyzed using one-way analysis of variance followed by Newman-Keuls test. * $p<0.05$ compared to the saline group. 
Table 3. Effect of bergenin on hematological analyses after 14 consecutive days.

\begin{tabular}{lcc}
\hline Hematological analyses & Saline & BG 2,000 mg/kg \\
\hline No of red blood cells $\left(\times 106 / \mathrm{mm}^{3}\right)$ & $5.65 \pm 3.6$ & $5.1 \pm 1.53$ \\
Hematocrit $(\%)$ & $40.66 \pm 0.3$ & $40.66 \pm 0.66$ \\
Platelets $\left(10^{5} / \mathrm{mm}^{3}\right)$ & $8.22 \pm 1.21$ & $7.34 \pm 0.95$ \\
Hemoglobin $(\mathrm{g} / \mathrm{dl})$ & $16.83 \pm 0.18$ & $15.32 \pm 1.18$ \\
MCV (fl) & $72.49 \pm 4.07$ & $79.80 \pm 2.30$ \\
MCH (pg) & $30.05 \pm 2.01$ & 30.052 .28 \\
MCHC (\%) & $41.43 \pm 0.78$ & $37.96 \pm 3.42$ \\
Leukocytes $\left(\times 10^{3} / \mathrm{mm}^{3}\right)$ & $6.66 \pm 0.85$ & $5.51 \pm 1.36$ \\
Lymphocytes (\%) & $70.60 \pm 4.37$ & $70.00 \pm 3.78$ \\
Monocytes (\%) & $0.66 \pm 0.33$ & $0.33 \pm 0.33$ \\
Neutrophils $(\%)$ & $25.66 \pm 4.25$ & $27.66 \pm 3.75$ \\
Eosinophils $(\%)$ & $3 \pm 0.57$ & $2.00 \pm 0.57$ \\
\hline
\end{tabular}

Values are expressed as mean \pm SEM. Results were analyzed using one-way analysis of variance followed by Newman-Keuls test. ${ }^{*} p<0.05$ compared to the saline group.

Table 2. Effect of bergenin on biochemical analyses of plasma after 14 consecutive days.

\begin{tabular}{lcc}
\hline Analyse bichemical & Salina & BG 2,000 mg/kg \\
\hline Creatinine (mg/dl) & $0.23 \pm 0.033$ & $0.20 \pm 0.00$ \\
Urea (mg/dl) & $61.68 \pm 3.14$ & $42.10 \pm 3.80$ \\
Total bilirubin (mg/dl) & $4.17 \pm 0.18$ & $6.06 \pm 0.12$ \\
Direct bilirubin (mg/dl) & $2.78 \pm 0.30$ & $5.12 \pm 0.31$ \\
Indirect bilirubin (mg/dl) & $1.39 \pm 0.33$ & $0.94 \pm 0.19$ \\
AST (U/l) & $2 \pm 0$ & $2 \pm 0$ \\
ALT (U/l) & $65.77 \pm 19.23$ & $56.08 \pm 6.85$ \\
Glucose (mg/dl) & $85.68 \pm 11.73$ & $42.93 \pm 10.73$ \\
Potassium (mmol/l) & $70.89 \pm 3.41$ & $71.91 \pm 3.70$ \\
Sodium (mmol/l) & $151.09 \pm 1.46$ & $154.13 \pm 5.88$ \\
Chlorine (mmol/l) & $118.45 \pm 2.46$ & $116.16 \pm 0.74$ \\
Calcium (mmol/l) & $0.02 \pm 0.0$ & $0.02 \pm 0.00$ \\
\hline
\end{tabular}

Values are expressed as mean \pm SEM. Results were analyzed using one-way analysis of variance followed by Newman-Keuls test. ${ }^{*} p<0.05$ compared to the saline group.

kidneys, heart, and liver also showed no histopathological changes between groups (data not shown).

\section{CONCLUSION}

Our study demonstrated that the BG showed antiinflammatory activity against different mediators of inflammation. BG also reduced vascular bearing, adhesion, and neutrophil migration, and consequently, minimized the damage caused by oxidative stress and lipid peroxidation. BG did not present toxic effects in the evaluated tests, evidencing its potential as an active ingredient for new drugs. However, it is necessary to conduct more detailed studies on mechanisms of action for BG.

\section{ACKNOWLEDGMENTS}

The authors would like to thank the National Council of Technological and Scientific Development, CNPq (Process 441859/2014-3, Brazil) and the Research Foundation for the State of Piauí-Brazil FAPEPI, for financial support for this work.

\section{CONFLICT OF INTEREST}

All authors of this study declare that there are no financial or commercial conflicts of interest.

\section{REFERENCES}

Aghajanian A, Wittchen ES, Allingham MJ, Garrett TA, Burridge $\mathrm{K}$. Endothelial cell junctions and the regulation of vascular permeability and leukocyte transmigration. J Thromb Haemost, 2008; 6:1453-60.

Akram M, Kim KA, Kim ES, Syed AS, Kim CY, Lee JS, Bae ON. Potent antiinflammatory and analgesic actions of the chloroform extract of Dendropanax morbifera mediated by the Nrf2/HO-1 pathway. Biol Pharm Bull, 2016; 39:728-36.

Almeida AAC, Silva RO, Nicolau LAD, de Brito TV, de Sousa DP, Barbosa ALR, de Freitas RM, Lopes LS, Medeiros JVR, Ferreira PMP. Physio-pharmacological investigations about the anti-inflammatory and antinociceptive efficacy of (+)-limonene epoxide. Inflammation, 2017; 40:511-22.

Ashour ML, Youssef FS, Gad HA, El-Readi MZ, Bouzabata A, Abuzeid RM, Mansour S, Wink M. Evidence for the anti-inflammatory activity of Bupleurum marginatum (Apiaceae) extracts using in vitro and in vivo experiments supported by virtual screening. J Pharm Pharmacol, 2018; 70:952-63.

Bajracharya GB. Diversity, pharmacology and synthesis of bergenin and its derivatives: potential materials for therapeutic usages. Fitoterapia, 2015; 101:133-52.

Barth CR, Funchal GA, Luft C, Oliveira JR, Porto BN, Donadio MV. Carrageenan-induced inflammation promotes ROS generation and neutrophil extracellular trap formation in a mouse model of peritonitis. Eur J Immunol, 2016; 46:964-70.

Bhatia D, Paliwal SK. Membrane stabilization, inhibition of 'histamine and prostaglandin synthesis' mediated anti inflammatory response of some indigenous plants. Int J Pharmacogn, 2014; 1:660-7.

Bradley PPMD, Priebat DMD, Christensen RDMD, Rothstein MD. Measurement of cutaneous inflammation: estimation of neutrophil content with an enzyme marker. J Invest Dermatol, 1982; 78:206-8.

Brito GA, Souza MH, Melo-Filho AA, Hewlett EL, Lima AA, Flores CA, Ribeiro RA. Role of pertussis toxin A subunit in neutrophil migration and vascular permeability. Infect Immun, 1997; 65:1114-8.

Buadonpri W, Wichitnithad W, Rojsitthisak P, Towiwat P. Synthetic curcumin inhibits carrageenan-induced paw edema in rats. J Health Res, 2009; 23:11-6.

Cano PM, Vargas A, Lavoie JP. A real-time assay for neutrophil chemotaxis. Biotechniques, 2016; 60:245-51.

Cao Y, Wang J, Su G, Wu Y, Bai R, Zhang Q, Gao X, Chun L, Chen S, Tu P, Chai X. Anti-myocardial ischemia effect of Syringa pinnatifolia Hemsl. By inhibiting expression 26 of cyclooxygenase -1 and -2 in myocardial tissues of mice. J Ethnopharmacol, 2016; 187:259-68.

Chen D, Bia A, Dong X, Jiang Y, Rui B, Liu J, Yin Z, Luo L. Luteolin exhibits anti-inflammatory effects by blocking the activity of heat shock protein 90 in macrophages. Biochem Biophy Res Commun, 2014; 443:326-32.

Chimona TS, Panayiotides JG, Papadakis CE, Helidonis ES, Velegrakis GA. Antihistamine effects on experimental middle ear inflammatory model. Eur Arch Otorhinolaryngol, 2008; 265:899-905.

Chintalwar G, Jain A, Sipahimalani A, Banerji A, Sumariwalla P, Ramakrishnan R, Sainis K. An immunologically active arabinogalactan from Tinospora cordifolia. Phytochemistry, 1999; 52:1089-93.

Daham K, James A, Balgoma D, Kupczyk M, Billing B, Lindeberg ARN, Henriksson E, Garret AF, Wheelock C, Dahlen SE, Dahlén B. Effects of selective COX-2 inhibition on allergen-induced bronchoconstriction and airway inflammation in asthma. J Allergy Clin Immunol, 2014; 134:306-13.

Fayngerts SA, Wang Z, Zamani A, Sun H, Boggs AE, Porturas TP, Xie W, Lin M, Cathopoulis T, Goldsmith JR, Vourekas A, Chen YH. 
Direction of leukocyte polarization and migration by the phosphoinositidetransfer protein TIPE2. Nat Immunol, 2017; 18:1353-60.

Ferlazzo N, Cirmi S, Calapai G, Ventura-Spagnolo E, Gangemi S, Navarra M. Anti-inflammatory activity of Citrus bergamia derivatives: where do we stand? Molecules, 2016; 21:1273-2016.

Fezai M, Senovilla L, Jemaá M, Attia MB. Analgesic, antiinflammatory and anticancer activities of extra virgin olive oil. J Lipids, $2013 ; 2013: 1-7$.

Fortes ZB, Farsky SP, Oliveira MA, Leme JG. Direct vital microscopic study of defective leukocyte-endothelial interaction in diabetes mellitus. Diabetes, 1991; 40:1267-73.

Fukumitsu S, Villareal MO, Fujitsuka T, Ainda K, Isoda H. Antiinflammatory and anti-arthritic effects of pentacyclic triterpenoids maslinic acid through NF- kB inactivation. Mol Nutr Food Res, 2016; 60:399-409.

Furtado AA, Torres-Rêgo M, Lima MCJS, Bitencourt MAO, Estrela AB, Silva NS, Siqueira EMS, Tomaz JC, Lopes NP, Silva-Júnior AA, Zucolotto SM, Pedrosa MFF. Aqueous extract from Ipomoea asarifolia (Convolvulaceae) leaves and its phenolic compounds have antiinflammatory activity in murine models of edema, peritonitis and air-pouch inflammation. J Ethnopharmacol, 2016; 192:225-35.

Gao XJ, Guo MY, Zhang ZC, Wang TC, Cao YG, Zhang NS. Bergenin plays an anti-inflammatory role via the modulation of MAPK and NF- $\mathrm{kB}$ signaling pathways in a mouse model of LPS-induced mastitis. Inflamm, 2015; 38:1142-50.

Gomes BS, Neto BPS, Lopes EM, Cunha FVM, Araújo AR, Wanderley CWS, Wong DVT, Júnior RCPL, Ribeiro RA, Sousa DP, Medeiros JVR, Oliveira RCM, Oliveira FA. Anti-inflammatory effect of the monoterpene myrtenol is dependent on the direct modulation of neutrophil migration and oxidative stress. Chem Biol Interact, 2017; 273:73-81.

Gros A, Ollivier V, Ho-Tin-Noé B. Platelets in inflammation: regulation of leukocyte activities and vascular repair. Front immunol, 2015; 5:678.

Herenius MM, Oliveira AS, Wijbrandts CA, Gerlag DM, Tak PP, Lebre MC. Anti-TNF therapy reduces serum levels of chemerin in rheumatoid arthritis: a new mechanism by which anti-TNF might reduce inflammation. PLoS One, 2013; 8:57802.

Herr N, Mauler M, Witsch T, Stallmann D, Schmitt S, Mezger J, Bode C, Duerschmied D. Acute fluoxetine treatment induces slow rolling of leukocytes on endothelium in mice. PLoS One, 2014; 9:88316.

Herrmann F, Lindemann A, Gauss J, Mertelsmann R. Cytokinestimulation of prostaglandin synthesis from endogenous and exogenous arachidonic acids in polymorphonuclear leukocytes involving activation and new synthesis of cyclooxygenase. Eur J Immunol, 1990; 20:2513-6.

Huang GJ, Deng JS, Huang SS, Chang C, Chang TN, Shie PH, Kuo YH. Anti-inflammatory Activities of $6 \beta$-Acetoxy- $7 \alpha-$ hydroxyroyleanone from Taiwania cryptomerioides Hayata ex vivo and in vivo. J Agric Food Chem, 2011; 59:11211-8.

Intini FP, Zajac J, Novohradsky V, Saltarella T, Pacifico C, Brabec V, Giovanni N, Kasparkova J. Novel antitumor platinum(ii) conjugates containing the nonsteroidal anti-inflammatory agent diclofenac: synthesis and dual mechanisms of antiproliferative effects. Inorg Chem, 2017; 56:1483-97.

Jang M, Jeong SW, Cho SK, Ahn KS, Lee JH, Yang DC, Kim JC. Anti-inflammatory effects of an ethanolic extract of guava (Psidium guajava L.) leaves in vitro and in vivo. J Med Food, 2014; 17:678-85.

Jin J, Chang Y, Wei W, He YF, Hu SS, Wang D, Wu YJ. Prostanoid EP1 receptor as the target of (-)-epigallocatechin- 3-gallate in suppressing hepatocellular carcinoma cells in vitro. Acta Pharmacol Sin, 2012; 33:701-9.

Kalokasidis K, Molyva D, Mirtsou V, Kokkas B, Goulas A. Evidence for the contribution of tumour necrosis factor in edema formation induced by histamine in the hind paw of the rat. Inflamm Res, 2009; $58: 437-40$.

Kim SH, Choi CH, Kim SY, Eun JS, Shin TY. Anti-allergic effects of Artemisia iwayomogi on mast cell-mediated allergy model. Exp Biol Med, 2005; 230:82-8.
Kiraly AJ, Soliman E, Jenkins A, Van Dross RT. Apigenin inhibits COX-2, $\mathrm{PGE}_{2}$, and $\mathrm{EP} 1$ and also initiates terminal differentiation in the epidermis of tumor bearing mice. Prostag Leukotr Ess, 2016; 104:44-53.

Kwiecien S, Jasnos K, Magierowski M, Sliwowski Z, Pajdo R, Brzozowski B, Mach T, Wojcik D, Brzozowski T. Lipid peroxidation, reactive oxygen species and antioxidative factors in the pathogenesis of gastric mucosal lesions and mechanism of protection against oxidative stress-induced gastric injury. J Physiol Pharmacol, 2014; 65:613-22.

Maling HM, Webster ME, Williams MA, Anderson Junior W. Inflammation induced by histamine, serotonin, bradykinin and compound 48-80 in the rat: antagonists and mechanisms of action. J Pharmacol Exp Ther, 1974; 191:300-10.

Marino A, Paterniti I, Cordaro M, Morabito R, Campolo M, Navarra M, Esposito E, Cuzzocrea S. Role of natural antioxidants and potential use of bergamot in treating rheumatoid arthritis. Pharma Nutr, 2015; 3:53-9.

Medzhitov R. Origin and physiological roles of inflammation. Nature, 2008; 454:428-35.

Mitra S, Mukherjee K, Biswas S, Banerjee ER. Prophylactic use of fisetin in thioglycollate-induced peritonitis in mice. Biol Syst, 2015; $4: 1-2$.

Muller WA. How endothelial cells regulate transmigration of leukocytes in the inflammatory response. Am J Pathol, 2014; 184:886-96.

Nishikawa H, Kitani S. Tea catechins have dual effect on mast cell degranulation induced by compound 48/80. Int Immunopharmacol, 2008; 8:1207-15.

Nunes-Neto PA, Peixoto-Sobrinho TJDS, Silva Júnior ED, Silva JL, Oliveira ARS, Pupo AS, Araújo AV, Costa-Silva JH, Wanderley AG. The effect of Schinus terebinthifolius Raddi (Anacardiaceae) Bark extract on histamine- induced paw edema and ileum smooth muscle contraction. Evid Based Complement Alternat Med, 2017; 2017:1-10.

Nunomura RCS, Oliveira VG, da Silva SL, Nunomura SM. Characterization of bergenin in Endopleura uchi bark and its antiinflammatory activity. J Braz Chem Soc, 2009; 20:1060-4.

Odobasic D, Kitching AR, Holdsworth SR. Neutrophil-mediated regulation of innate and adaptive immunity: the role of myeloperoxidase. J Immunol Res Ther, 2016; 2016:1-11.

OECD. Organization for economic Cooperantion and Development. Acute Toxic Class Method (Test No. 423), 2001; 423:1-14.

Offergeld R, Reinecker C, Gumz E, Schrum S, Treiber R, Neth RD, Gohla SH. Mitogenic activity of high molecular polysaccharide fractions isolated from the cuppressaceae Thuja occidentalis L. enhanced cytokine-production by thyapolysaccharide, g-fraction (TPSg). Europe PMC, 1992; 6:189-91.

Oliveira CM, Nonato FR, Lima FO, Couto RD, David JP, David JM, Soares MBP, Villarreal CF. Antinociceptive properties of bergenin. J Nat Prod, 2011; 74:2062-8.

Oliveira GAL, Oliveira GLS, Nicolau LAD, Mafud AC, Batista LF, Mascarenhas YP, Souza LKM, David JM, Pinto LS, Alves CQ, Medeiros JVR. Bergenin from Peltophorum dubium: isolation, characterization, and antioxidant activities in non-biological systems and erythrocytes. Med Chem, 2017; 13:592-603.

Oliveira GAL, Oliveira, GLS, Rezende Junior LM. Cell toxicity and hemolytic potential of an isolated molecule from Peltophorum dubium (Spreng). Toxicol Lett, 2015; 2:192.

Pérez MJ, Cuello AS, Zampini IC, Ordoñez RM, Alberto MR, Quispe C, Hirschmann-Schmeda G, Isla MI. Polyphenolic compounds and anthocyanin content of Prosopis nigra and Prosopis alba pods flour and their antioxidant and antiinflammatory capacities. Food Res Int, 2014; 64:762-71.

Perkins JR, Sanak M, Canto G, Blanca M, Cornejo-García JA. Unravelling adverse reactions to NSAIDs using systems biology. Trends Pharmacol, 2015; 36:172-80.

Pietrosimone KM, Liu P. Contributions of neutrophils to the adaptive immune response in autoimmune disease. World J Transl Med, $2015 ; 4: 60-8$ 
Ren X, Ma S, Wang J, Tian S, Fu X, Liu X, Li Z, Zhao B, Wang X. Comparative effects of dexamethasone and bergenin on chronic bronchitis and their anti-inflammatory mechanisms based on NMR metabolomics. Mol Biosyst, 2016; 12:1938-47.

Rielland M, Cantor DJ, Graveline R, Hajdu C, Mara L, de Diego Diaz B, Hajdu C, Miller G, David G. Senescence-associated SIN3B promotes inflammation and pancreatic cancer progression. J Clin Invest, 2014; 124:2125-35.

Rosa SIG, Rios-Santos F, Balogun SO, de Oliveira Martins DT. Vitexin reduces neutrophil migration to inflammatory focus by downregulating pro-inflammatory mediators via inhibition of $\mathrm{p} 38, \mathrm{ERK} 1 / 2$ and JNK pathway. Phytomedicine, 2016; 23:9-17.

Sancilio LF. Evans blue-carrageenan pleural effusion as a model for the assay of nonsteroidal antirheumatic drugs. J Pharmacol Exp Ther, 1969; 168:199-204.

Shah MR, Arfan M, Amin H, Hussain Z, Qadir MI, Choudhary MI, VanDerveer D, Mesaik MA, Soomro S, Jabeen A, Khan IU. Synthesis of new bergenin derivatives as potent inhibitors of inflammatory mediators NO and TNF-alpha. Bioorg Med Chem Lett, 2012; 22:2744-7.

Silva IS, Nicolau LA, Sousa FB, de Araújo S, Oliveira AP, Araújo TS, Souza LKM, Martins CS, Aquino PEA, Carvalho LL, Silva RO, Rolim-Neto PJ, Medeiros JVR. Evaluation of anti-inflammatory potential of aqueous extract and polysaccharide fraction of Thuja occidentalis Linn in mice. Int J Biol Macromol, 2017; 105:1105-16.

Silva RO, Damasceno SRB, Silva IS, Silva VG, Brito FC, Teixeira AEA, Nunes GBL, Camara CA, Filho JMB, Gutierrez SJC, Ribeiro RA, Souza MHLP, Barbosa ALR, Freitas RM, Medeiros JVR. Riparin A, a compound from Aniba riparia, attenuate the inflammatory response by modulation of neutrophil migration. Chem Bio Interacions, 2015; 5:55-63.

Silva RO, Sousa FB, Damasceno SR, Carvalho NS, Silva VG, Oliveira FR, Sousa DP, Aragão KS, Barbosa AL, Freitas RM, Medeiros JV. Phytol, a diterpene alcohol, inhibits the inflammatory response by reducing cytokine production and oxidative stress. Fundam Clin Pharmacol, 2014; 28:455-64.

Silva VG, Silva RO, Damasceno SRB, Carvalho NS, Prudêncio RS, Aragão KS, Guimarães MA, Campos SA, Veras LMC, Godejohanns M, Leite JRSA, Barbosa ALR, Medeiros JVR. Anti-inflammatory and antinociceptive activity of epiisopiloturine, an imidazole alkaloid isolated from Pilocarpus microphyllus. J Nat Prod, 2013; 76:1071-7.

Singh P, Singh I, Sudhan ZA, Yadav P. Bioflavonoids and natural health: an overview. IOSR JDMS, 2015; 14:84-7.

Singh TP, Schön MP, Wallbrecht K, Gruber-Wackernagel A, Wang XJ, Wolf P. Involvement of IL-9 in Th17-associated inflammation and angiogenesis of psoriasis. PLoS One, 2013; 8:51752.

Sousa-Neto BP, Gomes BS, Cunha FV, Arcanjo DD, Gutierrez SJ, Souza MF, Almeida FR, Oliveira FA. Antiedematogenic activity of the indole derivative $\mathrm{N}$-salicyloyltryptamine in animal models. Anais Acad Brasil Ciências, 2018; 90:185-94.

Sullivan PW, Ghushchyan VH, Globe G, Schatz M. Oral corticosteroid exposure and adverse effects in asthmatic patients. J Allergy Clin Immunol, 2018; 141:110-6.

Taams LS. Inflammation and immune resolution. Clin Exp Immunol, 2018; 193:1-2.

Takahashi H, Kosaka M, Watanabe Y, Nakade K, Fukuyama Y. Synthesis and neuroprotective activity of bergenin derivatives with antioxidant activity. Bioorg Med Chem, 2003; 11:1781-8.

Thao NP, Luyen BTT, Widowati W, Fauziah N, Maesaroh M, Herlina T, Manzoor Z, Ali L, Koh YS, Kim YH. Anti-inflammatory flavonoid C-glycosides from Piper aduncum leaves. Planta Med, 2016; 82:1475-81.
Trevisan G, Rossato MF, Hoffmeister C, Muller LG, Pase C, Córdova MM, Rosa F, Tonello R, Hausen BS, Boligon AA, Moresco RN, Athayde ML, Burgger ME, Santos AR, Ferreira J. Antinociceptive and antiedematogenic effect of pecan (Carya illinoensis) nut shell extract in mice: a possible beneficial use for a by-product of the nut industry. J Basic Clin Physiol Pharmacol, 2014; 25:401-10.

Uchiyama M, Mihara M. Determination of malonaldehyde precursor in tissues by thiobarbituric acid test. Anal Biochem, 1978; $86: 271-8$.

Vasconcelos AG, Amorim AGN, Santos RC, Souza JMT, Souza LKM, Araújo TSL, Nicolau LAD, Carvalho LL, Aquino PEA, Martins CS, Ropke CD, Soares PMG, Kuckelhaus SAS, Medeiros JVR, Leite JRSA. Lycopene rich extract from red guava (Psidium guajava L.) displays antiinflammatory and antioxidant profile by reducing suggestive hallmarks of acute inflammatory response in mice. Food Res Int, 2017; 99:959-68.

Wang K, Li YF, Lv Q, Li XM, Dai Y, Wei ZF. Bergenin, acting as an agonist of PPAR $\gamma$, ameliorates experimental colitis in mice through improving expression of SIRT1, and therefore inhibiting NF-kB-mediated macrophage activation. Front Pharmacol, 2018; 8:981.

Wang Q, Wu J, Wu X, Tai W, Dai N, Wu R, Han N. Antiinflammatory and analgesic effects of two new flavone C-glycosides from Panzeria alaschanica. Monatsh Chem Chem Mon, 2015; 146:1025-30.

Werner I, Guo F, Kiessling AH, Juengel E, Relja B, Lamm P, Stock U, Moritz A, Beiras Fernandez A. Treatment of endothelial cell with flavonoids modulates transendothelial leukocyte migration. Phlebology, 2015; 30:405-11.

Wilhelm DL. Mechanisms responsible for increased vascular permeability in acute inflammation. Agents Actions, 1973; 3:297-306.

Wilson RH, Booth AN, DeEds F. Protection by flavonoids against histamine shock. Exp Biol Med, 1951; 76:540-2.

Yang S, Yu Z, Wang L, Yuan T, Wang X, Zhang X, Wang J, Lv Y, $\mathrm{Du}$ G. The natural product bergenin ameliorates lipopolysaccharide-induced acute lung injury by inhibiting NF-kappaB activition. J Ethnopharmacol, 2017; 200:147-55.

Yang X, Gao X, Du B, Zhao F, Feng X, Zhang H, Zhu Z, Xing J, Han Z, Tu P, Chai X. Ilex asprella aqueous extracts exert in vivo antiinflammatory effects by regulating the NF- $\mathrm{kB}$, JAK2/STAT3, and MAPK signaling pathways. J Ethnopharmacol, 2018; 225:234-43.

Zygmunt M, Chłoń-Rzepa G, Sapa J. Analgesic and antiinflammatory activity of 7-substituted purine-2, 6-diones. Pharmacol Rep, 2014; 66:996-1002.

How to cite this article:

Oliveira GAL, Araujo AKS, Pacheco G, Oliveira AP, Carvalho

JL, Chaves LS, Sousa GC, Lopes ALF, Silva PC, Leódido ACM, Nogueira KM, Souza LKM, Araújo TL, Nicolau LAD, Medeiros JVR. Anti-inflammatory properties of bergenin in mice. J Appl Pharm Sci, 2019; 9(07):069-077. 